Document downloaded from:

http://hdl.handle.net/10251/86323

This paper must be cited as:

Woolley, RD.; Sánchez-Barrioluengo, M.; Turpin, T.; Marceau, J. (2015). Research collaboration in the social sciences: What factors are associated with disciplinary and interdisciplinary collaboration?. Science and Public Policy. 42(4):567-582. doi:10.1093/scipol/scu074.

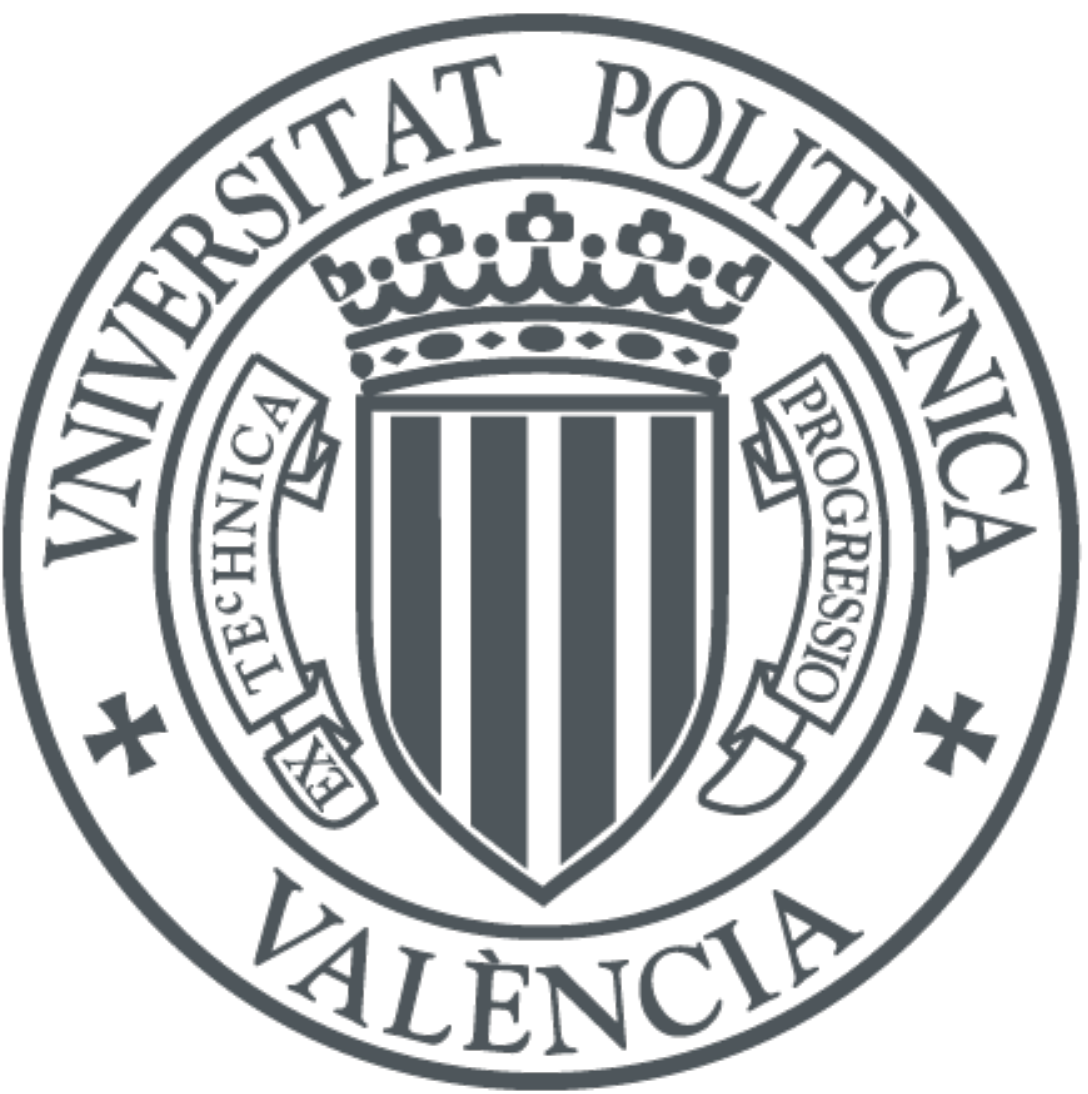

The final publication is available at

http://doi.org/10.1093/scipol/scu074

Copyright Oxford University Press (OUP)

Additional Information 
The revised peer reviewed version of this article has been accepted for publication in Science and Public Policy, Published by Oxford University Press.

doi:10.1093/scipol/scu074

\section{Research collaboration in the social sciences: What factors are associated with disciplinary and interdisciplinary collaboration?}

Richard Woolley ${ }^{\text {a }}$ *

Email: ricwoo@ingenio.upv.es

Mabel Sánchez-Barrioluengo ${ }^{\mathrm{a}}$

Email: msbarrioluengo@ingenio.upv.es

Tim Turpin ${ }^{\mathrm{b}}$

Email: t.turpin@uws.edu.au

Jane Marceau $^{\mathrm{c}}$

Email: jmarceau@iinet.net.au

${ }^{a}$ INGENIO (CSIC-UPV), Polytechnic University of Valencia (UPV), Valencia, Spain.

${ }^{\mathrm{b}}$ College of Business, University of Western Sydney, Parramatta NSW, Australia.

${ }^{\mathrm{c}}$ University of New South Wales, Sydney NSW, Australia.

* Corresponding author:

Richard Woolley

INGENIO (CSIC-UPV)

Universitat Politècnica de València

Ciudad Politécnica de la Innovación

Edif 8E 4 Planta

Camino de Vera s/n

Valencia 46022

Spain

Tel: +34 963877007 x78430

Email address: ricwoo@ingenio.upv.es 


\section{Research collaboration in the social sciences: What factors are associated with disciplinary and interdisciplinary collaboration?}

\section{Introduction}

Research collaboration is a topic of considerable interest to scholars of science and research policy (Katz and Martin, 1997). The structure of science has been observed to change over time, with research collaboration becoming more commonplace due, in part, to 'big science' and the heightened complexity of, and specialisation within, scientific fields (Blau, 1994; Melin, 2000; Price, 1963; Wray, 2005). The proliferation of specialisations underlies the argument that interdisciplinary collaborations are important in the interests of integrating knowledge from diverse points of the scientific compass (Liu et al., 2012). This has in turn driven the emergence of new forms of organization of collaboration (Chompalov et al., 2001; Porac et al., 2004) and diverse mechanisms for collaboration between different types of organisation (D’Este and Fontana, 2007).

Changes have also occurred in the demands being made of science. A variety of descriptive accounts have addressed the closer integration of publicly-funded education and research and private economic exploitation (Gibbons et al., 1994; Etzkowitz et al., 2000; Ziman, 2000). The emergence of broad new research challenges, such as environmental sustainability and public health problems, has driven the mobilization of diverse types of disciplinary knowledge within collaborative frameworks (Rosenfeld, 1992; Tappeiner et al., 2007). Policy initiatives and governance systems built around priorities, accountabilities and evaluation (Whitley et al., 2010) have variously sought to promote excellence, relevance, societal impact, applied research and interdisciplinarity (Bruce et al., 2004; European Commission Research Directorate-General, 2007; Gläser, 2012). Normative demands for interdisciplinary research have thus been grounded in logics of both public accountability and innovation flowing from the valorisation of closer integration between science and societal needs (Barry et al., 2008).

It is unclear what impact the emergence of these new or modified drivers of research collaboration and the valorisation of interdisciplinarity have had on patterns of collaboration, particularly in relation to the social sciences. Most studies of research collaboration focus on the sciences (Bozeman et al. 2013; Perkmann et al. 2013), so an important contribution of this paper is that it investigates the factors associated with collaboration in the social sciences. This study contributes to empirical research that focuses at the individual researcher level (Melin, 2000), concentrating on factors contributing to collaborative activity (Bozeman and 
Corley, 2004; Gaughan and Corley, 2010; van Rijnsoever and Hessels, 2011) by analysing relationships between the volume of research collaborations and the diversity of work experience, internationalised social capital networks, and researchers' orientation toward basic or applied research. Throughout our analyses we differentiate between disciplinary and interdisciplinary collaboration, to assess whether the factors associated with increased numbers of collaborations vary between the two.

\section{Research collaboration, the social sciences and interdisciplinarity}

A classic understanding of research collaboration views it as a process integral to the social and intellectual organisation of scientific disciplines (Whitley 2000). Since Merton's (1973) seminal work on the Matthew effect, it has been well understood that collaborator choice is an important strategic element affecting individual career trajectories. Decisions to collaborate involve calculations regarding reputation, credibility and the acquiring of prestige by association (Crane 1972), particularly in relation to visible markers of joint accomplishment such as co-authorship of papers (Laudel, 2002). Trust in a collaborator's capability to make a contribution (Shapin 1994) and expectations of reciprocity in terms of their effort and application of scientific resources (Mauss 1950 [1990]; Vinck 2010) are fundamental at the interpersonal level. The informal dimension of interpersonal trust in collaborations is also important (Clark 2011; Ubfal and Maffioli 2011). Collaborative scientific work is formalised in co-authorships, contributing to research performance evaluation and cycles of credibility that directly impact the allocation of scientific resources (Merton, 1973). In this process, collaboration thus plays an important role in the social organisation of science as a relational field of positions (Bourdieu, 1975). ${ }^{1}$

A resource-based view of collaboration has variously shown it to provide access to skills, tacit knowledge, funding and research infrastructure (Katz and Martin, 1997; Melin, 2000). Networks of collaborators are thus vital for mobilizing the resources required for research (Latour and Woolgar 1986). Collaborations thus provide both a context for learning, knowledge transfer and skills development (human capital) and facilitate network building and professional connections (social capital) (Bozeman et al. 2001), in a process of trade and exchange that can extend beyond academic institutions and into private firms (Bozeman and Gaughan 2007; Deitz and Bozeman 2005; Ensign 2009). Formal collaboration between

\footnotetext{
${ }^{1}$ Ultimately, collaborating with those colleagues whose positions allow them to determine the 'stakes of the game' (i.e. the defining research questions or problems) within a particular field or sub-field will be strategically the most rewarding, in that it leads to the greatest level of homology between individual interests and institutional arrangements (Bourdieu, 1975).
} 
organisations or organisational units on large scale research projects may also bring scientists into interpersonal collaboration relationships, but with different implications for the type of trust that is necessary for successful achievement of research goals (Shrum et al. 2001). Today most research is collective and cognitive resources are distributed across a research team (Beaver, 2001), many of which will be interdisciplinary and involve inter-organisational alliances (Chompalov et al. 2001).

The emergence of resource-based understandings of research collaboration coincides with changes in the demands being made of science (Gibbons et al. 1994). The promotion of societal impact impact (Bornmann 2013) and knowledge application, particularly through funding and evaluation system levers (Whitley et al. 2010), has been assumed to drive collaboration patterns toward more interdisciplinarity (Hagstrom 1965). However, a link between applied research and interdisciplinarity remains unproven (Katz and Martin 1997). In the remainder of this section we review relevant literature regarding research collaboration in the social sciences, factors contributing to research collaboration, and the emergence of interdisciplinarity, bringing these strands together in our research hypotheses.

\subsection{Collaboration in the social sciences}

A relatively small number of studies have focussed specifically on research collaboration in the social sciences (SS). Endersby (1996) studied co-authorship in social science journals from a range of discipline and found around half of all papers had multiple authors. Leahey and Reikowksy (2008) found that the extent of specialization in sociology is linked to distinctive collaboration strategies. The majority of sociology co-authorships (70\%) followed a strategy of reinforcing common approaches to shared research topics (2008, p.436). Lee (1996) found social scientists had a far more negative outlook on applied research collaborations than natural and physical scientists and engineers. Rhoton and Firman (2007) found that women in SS and the arts and humanities spent more time on interdisciplinary projects than their male colleagues, as was the case in physical and engineering and medical fields. Interdisciplinary collaboration between the social and health sciences has become increasingly common with the rise of holistic public health projects and programs (Rosenfeld, 1992). Olmos-Peñuela and colleagues (2014a) found that SS and humanities research groups collaborate with outside partners on knowledge transfer activities, including consultancy, contract research, joint research projects and training. However, much remains unclear regarding both disciplinary and interdisciplinary collaboration in SS. 


\subsection{Factors related to scientists' collaborations}

There is a large body of empirical research focused on research collaboration, in particular the activities and channels of collaboration between academic researchers and industry partners (for reviews see Bozeman et al. 2013; Perkmann et al. 2013). Collaboration with industry is a factor that has been shown to have beneficial effects on scientific productivity (Lee and Bozeman, 2005; Lin and Bozeman, 2006). A range of different personal values and motivations have also been shown to influence university researchers' collaborations with industry partners (Lam 2011; Tartari and Breschi 2011). D’Este and Perkmann (2011) found that academics are motivated to collaborate with industry by commercialization opportunities, learning, accessing funding and in-kind resources, while academic peers have also been shown to influence the propensity to collaborate with firms (Tartari et al. 2014).

Since Merton (1973) it has been well understood that achievement and reward are mutually reinforcing aspects of research careers. Researchers with longevity and standing in a particular specialisation have progressed significantly in their careers within a peer community, usually matched by progress higher up the ranking scale of positions within research performing organisations (Glaser and Laudel, 2007 \& 2008). Career longevity can equally be understood to indicate significant accumulation of skills, knowledge and social capital networks, including collaborative relationships that are conjointly constitutive of the career trajectory (Bozeman et al., 2001; Bozeman and Corley, 2004). Empirical studies have found that the number of professional jobs in science and research is a direct indicator of the opportunities to build the networks which can lead to an increase in the number of collaborators (Dietz and Bozeman, 2005; Lee and Bozeman, 2005). Van Rijnsoever and Hessels (2011) established a relationship between the length of the career and the number of collaborations. They found the number of collaborations tends to increase in the early stages of the career to an eventual peak, before declining in the later stages of the career. According to their results, the number of collaborations mapped onto the length of a career produces an inverted U-shaped curve (2011, p.467-8). Such a relationship has also been observed in relation to the rate of scientific publishing over the length of academic careers (Levin and Stephan, 1991).

Scientific collaboration can also benefit from diversity of work experience. Dietz and Bozeman (2005) explored the diversity of experience, particularly the benefits that can accrue to researchers’ productivity from industry employment. Lin and Bozeman (2006) found evidence of a connection between diverse career structures and increased productivity in 
patenting and, to a lesser extent, publications. A partial explanation for these benefits is through the enlarged pool of potential collaborators that networks reaching into industry (or other sectors) provide access to. This argument is support by the results of van Rijnsoever and Hessels (2011), who found a positive relationship between the number of disciplinary and interdisciplinary research collaborations and the number of previous positions held in both universities and firms. They also found a positive relationship between total collaboration and the number of previous positions held in universities.

A significant problem here is that this evidence is almost entirely based on science, technology, engineering and mathematics (STEM) research fields. The lack of specific evidence related to factors contributing to collaboration in the social sciences means that our expectation of a positive relationship between the extent of prior experience and the number of collaborations must be based on characteristics of STEM collaborations. Hence, we test:

Hypothesis 1 A positive relationship exists between the number of research collaborations and the number of previous relevant jobs.

Diversity of career experience can also be gained through geographic mobility. Diverse studies highlight the beneficial effects of mobility on science careers (Ackers, 2009; Zubieta, 2009) and national system capacity building (Mahroum, 2000; Jonkers, 2010). While organisational career incentives may tend to reward non-mobility in some national systems (Cruz-Castro and Sanz-Menéndez, 2010), support measures at the national and international level encourage researcher mobility, in many cases with the explicit aim of developing research collaboration across national boundaries (CEC, 2005; DIISR, 2011). Many studies have highlighted the role of mobility of postgraduate students and established researchers to the US and other science centres in the development of national science and research systems in Asia, for example (Krishna and Khadria, 2007; Saxenian, 2006; Song, 1997). Previous studies of research careers in Asia-Pacific have strongly indicated geographic mobility to be an important building block of productive international research collaborations (Turpin et al., 2010; Woolley et al., 2008). Studies based on co-authorship data have also shown that global linkages are now regularly a feature of research collaborations (Wagner, 2005). The link between international researcher mobility and globalised research collaborations thus appears well established in the literature. 
General population policy settings are also important to international connectedness, with the migration and mobility of the highly skilled argued to be beneficial to the knowledge capital (Williams, 2007) and innovation systems (Hart, 2006) of receiving countries. ${ }^{2}$ Migrant or mobile researchers can be assumed to have an enlarged base of contacts due to their dual (or multiple) personal and/or professional contexts. Based on previous survey work in the natural sciences (Turpin et al., 2010; Woolley et al., 2008), we expected a significant proportion of dual citizens and visitors (temporary or permanent residents) among our Australian-based respondents. To test for benefits of internationalisation of the workforce in enlarging the collaboration base we therefore assumed differences between those respondents with Australian citizenship only and all other respondents.

Hypothesis 2 Holders of international citizenship(s) will have higher numbers of research collaborations than holders of Australian citizenship only.

\subsection{The rise of interdisciplinary research}

Interdisciplinarity introduces an additional complicating variable to understanding relationships between research careers and collaboration. Interdisciplinarity does not necessarily involve collaboration. A single researcher may employ methods or ideas from multiple disciplines in their work (Rhoten and Firman, 2007). On the other hand, interdisciplinary collaboration may be specifically related to the sharing of ideas and disciplinary knowledge (Beaver and Rosen, 1978; Katz and Martin, 1997). Relatively new social science specialisations such as cultural studies, may also involve the conjoint training in, and application of, methods or frameworks from diverse disciplines (Barry et al., 2008). In general, collaboration can be considered a more efficient source of resources common in other disciplines than undertaking significant training, for example.

The rise of interdisciplinarity thus logically impacts researcher's collaboration strategies, potentially impacting their career trajectory. Collaborators may need to be found outside the peer community of their specialisation. For example, if collaboration across disciplines is required to access certain funding pools, then researchers may be inclined to adapt their

\footnotetext{
${ }^{2}$ Australia is a country of high levels of inward population flows with a policy accent on the skilled migration program and education exports. A significant proportion of these inward population flows take up Australian citizenship after periods as permanent residents (DIAC, 2011). Dual nationality is permitted in Australia, reducing impediments to processes of interaction and movement. In addition specific Visitor visas enable organisations, such as universities, to hire non-nationals for up to four years initially, with a reduced processing time than occurs through the Migration Program. Many second or third generation migrant families retain strong ties with countries of origin, including citizenship status where permitted. Australian-born dual citizens can also be assumed to have cultural, family and personal ties that may increase professional collaboration opportunities.
} 
research to suit the accessible interdisciplinary collaborators (Gläser, 2012). Bruce and colleagues (2004, p. 463), found that researchers are motivated to engage in interdisciplinary research by factors including disciplinary bottlenecks, transferring knowledge to the 'real world' and applying knowledge to user-driven research problems. On the other hand, there is also evidence suggesting that interdisciplinary research applications actually encounter negative discrimination in research funding and publication evaluation processes (Bruce et al., 2004; Laudel and Origgi, 2006) and are held in low regard by disciplinary colleagues (Bruce et al., 2004). Poor career structures for academic interdisciplinary researchers have been identified as one factor discouraging interdisciplinary research (Bruce et al., 2004, p.262).

Since Hagstrom (1965), it has been generally assumed that applied research is more interdisciplinary. Klein (1990) identified research and development (R\&D) problem-solving and healthcare as focal zones for interdisciplinarity. Foray and Gibbons (1995) similarly argued that having a focus on applying knowledge in a problem-solving context was conducive to interdisciplinary research approaches. Ziman (1994) argued that this was much more likely to be the case in some disciplines than in others. Carayol and Thi (2005) found that university researchers who had co-published with an industry-based researcher increased interdisciplinary involvement. They also found that a research lab that are less reliant on recurrent funding and more on multiple channels of project funding were more involved in problem-solving and interdisciplinary research. Thus while there are indications that applied research and problem-solving are associated with interdisciplinarity, this has not been conclusively demonstrated (Katz and Martin, 1997).

In the case of the social sciences, very little is known about interdisciplinary collaboration. Maasen (2000) found that a research group level collaboration between biologists and sociologists relied on a 'set of intersectional activities' including some problem orientation. Rhoton and Firman (2007) found women had a stronger orientation toward interdisciplinary projects that their male colleagues, including in the social sciences. Olmos-Peñuela and colleagues (2014) found that multidisciplinary social science research groups were most likely to collaborate through the channel of contract research. However, there is no strong evidence that applied social science research is connected to interdisciplinary collaboration. In formulating our hypothesis regarding interdisciplinary collaboration and applied research we therefore rely on the evidence from STEM fields. 
Hypothesis 3 Researchers who are oriented toward applied research will have more interdisciplinary collaborations than those oriented toward basic research.

\section{Research background}

The Australian context for researching social science collaboration includes certain distinct local characteristics. Australia has benefitted from strong flows of highly skilled migrants, with $48 \%$ of the $\mathrm{PhD}$ qualified population at Census 2006 being born overseas. The available evidence also suggests that around half of all foreign $\mathrm{PhD}$ students remain working in Australia a year after completion (Edwards et al., 2009, p.25). Social science graduates and post-graduate researchers are produced within an internationally competitive and OECDbenchmarked education system, characterised by a small number of top-100 ranked universities, an extensive export component (international students) and a domestic student body that is highly diverse culturally and around 60\% female. In 2009 female students completed $65 \%$ of a total of 1,084 domestic doctorates in social sciences, with a further 264 social science doctorates completed by international students (48\% females). Australian social science professionals publish significant numbers of papers in international journals (Butler, 2003) including a substantial proportion with internationally-based co-authors (Matthews et al., 2009). In this, the Australian context has strong interconnectedness with, and relevance to, international social science education and research concerns.

Research collaboration in Australia is advanced institutionally via large programs focused on end-user benefits, including the Commonwealth Scientific and Industrial Research Organisation (CSIRO) Flagship program and the Cooperative Research Centres (CRC) program (Productivity Commission, 2007). Interdisciplinarity is not discretely funded at a program level, however the focus on applied research and commercialisation within these major programs can be considered to indirectly promote interdisciplinarity (Turpin and Garrett-Jones, 2000). The position of the social sciences in relation to these large scale programs has been marginal historically. However, the introduction of social science-based CRCs was recommended by the most recent review of the program (O’Kane, 2008), and the first social science Centres have since been established. At the individual level, the Australian Research Council (ARC) Linkage program funds collaborative projects between academic researchers and public and private sector partners, with the accent on applied research, knowledge transfer and end-user benefit. Again the promotion of interdisciplinarity, including in the social sciences, can be considered more a by-product of support measures for applied research than a directly funded priority. 


\section{Methodology}

The study follows the approach of other recent investigations of research collaboration that have used self-report surveys to collect primary data (Boardman and Corley, 2008; Bozeman and Corley, 2004; Bozeman and Gaughan, 2011; van Rijnsoever and Hessels, 2011). In common with these studies, insight can be gained into research collaborations that may not have led to the co-authorship of journal articles or other types of output available to bibliometric studies. Methodologically, the paper takes a straightforward approach to the question of what constitutes interdisciplinarity, as other recent studies have done (Liu et al., 2012, Rafols and Meyer, 2010; van Rijnsoever and Hessels, 2011). Throughout what follows we use ‘interdisciplinary collaboration' to refer to collaborations across disciplinary divides and to subsume in one general term various more specific definitions. ${ }^{3}$ Disciplinary collaboration refers to collaborations within disciplines. ${ }^{4}$

\subsection{Data collection}

The data used here are from a survey of Australian-based social scientists. We sampled publications included in the ISI Web of Science Social Science Citation Index (SSCI) that included at least one Australian-based author, for the period January 2008 to March 2011. We sampled from a variety of SSCI subject areas ${ }^{5}$, in quantities equivalent to their contribution to the total number. ${ }^{6}$ The email addresses of Australian-based authors were subsequently used to form the sample for the survey. The strategy of recruiting a sample of potential respondents using paper authorships from the SSCI was twofold. First, we wanted to recruit social

\footnotetext{
${ }^{3}$ See Klein (2000) for a comprehensive discussion. We might have easily used the term cross-disciplinarity, which is also commonly used as a general category in the Australian context. However, interdisciplinarity fits straightforwardly with international literature.

${ }^{4}$ Gaps in knowledge about research collaboration are partly due to methodological challenges presented by defining and mapping scientific disciplines (Katz and Martin, 1997; Laudel, 2002). A discipline can be considered as a 'historically evolving and heterogeneous nexus of objects, problems, theories, texts, methods and institutions that are thought to be worth both contesting and defending' (Barry el al., 2008). Disciplines are also in part differentiated by their formal organisation, particularly within University departments (Becher and Trowler, 2001), their degree of dependency and task characteristics (Whitley, 2000), and are also responsible for disciplinary socialization processes through doctoral research training (Delamont et al., 2000). This complexity means sharply defined borders often cannot be assigned to scientific disciplines. Interdisciplinary collaboration thus constitutes the kind of multidimensional and complex research object regarding which only partial indicators can be constructed (Martin and Irvine, 1983).

${ }^{5}$ E-mail addresses were retrieved from a total of 11,119 publications (8,079 journal articles, 2,229 book reviews, 423 proceedings papers, 388 reviews). The SSCI subject areas of the papers included in the sample were: anthropology; business; business, finance; communication; demography; economics; environmental sciences; environmental studies; geography; history \& philosophy of science; industrial relations \& labour; information \& library science; international relations; law; management; operations research \& management science; planning \& development; political science; public administration; social sciences interdisciplinary; sociology; and urban studies.

${ }^{6}$ We were not using co-authorship of articles as an indicator of research collaboration (Laudel, 2002); research papers were simply used as a means to identify authors located in Australia and their email address. Authors of sole-authored papers are thus included in our sample.
} 
scientists who are 'active researchers' in the very limited evaluation sense of producing countable research outputs - in this case scientific publications. Second, we hoped to recruit social scientists working in organizations outside higher education, reasoning that interdisciplinary research outputs in Australia may also be linked to applied research and funding programs supporting the cross-sectoral organization of research collaboration (Turpin et al., 2011).

The survey was conducted online, with participants gaining access to the questionnaire via a link sent to their email address. The email contained a description of the survey and the research team, with the link taking participants to an introduction page that included further information including the ethics approval number. ${ }^{7}$ Online surveys have been argued to have some advantages, including gaining access to the study population (Roztocki, 2001) and higher efficiency (by number of surveys) and speed of response (Flaherty et al., 1998; Roztocki, 2001; Sheehan, 2001). However, disadvantages include the difficulty to determine the response rate (Fricker et al., 2005). This difficulty results from ascertaining non-response, which of course remains one of the main problems for the administration of all surveys.

\subsection{Respondents}

From an initial list of 5,200 e-mail targets, a total of 4,224 e-mail addressees were contactable, with undeliverable (836) and auto-reply absentee messages (159) being excluded. A total of 698 responses were received, representing a response rate of $17 \%{ }^{8}$ Two emails were sent out to as 'reminders', at intervals of eight days. Some authors suggest that the reminder in online surveys can affect both the response rate and its quality (Sánchez Fernández et al., 2009). In fact, responses received following reminders constitute a representative sample of non-respondents to previous invitations (Díaz de Rada, 2005). To avoid problems arising from non-response, we used responses to the main variables from the two reminders as a sample of non-respondents to check if there are differences between

\footnotetext{
${ }^{7}$ All research involving human subjects in Australia requires the online submission and approval of the National Ethics Application Form (NEAF). See http://www.neaf.gov.au

${ }^{8}$ If we were to venture an explanation for this relatively low response rate it would be largely due to research fatigue. Two other surveys targeting social scientists sent out invitations just prior to our planned launch date, such that we delayed our survey for a number of weeks and out of our preferred semester break window. The first competing survey focused on the use of social science research for policy development and program review and was conducted by respected academic colleagues as part of a national competitive grants funded project. The other focused on collaboration between researchers and the Australian Public Service and was conducted by the Australian Department of Industry (DIS). Without these surveys, which targeted much the same researcher base, it is likely the response rate would have been higher. The authors were alerted to this unfortunate timing when they received invitations to participate in these surveys themselves.
} 
groups. If statistically significant differences between respondents and non-respondents did not exist we could consider our respondents as a representative sample of our population.

Of the 698 responses, 84 containing significant missing values and 16 which could not be assigned to either initial or reminder groups for technical reasons were not taken into account in testing for non-response problems. Excluding these, there were 361 respondents to the initial invitation and 237 respondents to the two reminders. The main variables were the total number of research collaborations and the number of interdisciplinary research collaborations. Due to the lack of normality of the two variables, we performed a non-parametric statistical test to check differences between the groups. In this case, we used U-Mann Whitney test (Wilcoxon, 1945), which utilizes the mean ranks instead of comparing means and is thus more sensitive to outliers. Neither variable has significant differences (Table 1), indicating the responses of those who answered the survey at the first invitation and those who answered later are the same and we had avoided problems of non-response bias. For the remaining analyses we considered all the responses as a representative sample of our population. A total of $87.9 \%$ of the respondents had one or more research collaborations, while $72.4 \%$ had one or more interdisciplinary collaborations.

Table 1. Differences between respondents to first and subsequent invitations to participate

\begin{tabular}{lccc}
\hline & First invite & Reminder & U-Mann Withney \\
\cline { 2 - 3 } & Mean (S.D.) & Mean (S.D.) & Z (p-value) \\
\hline Total Research collaboration & $5.98(5.75)$ & $5.64(5.59)$ & $-1.205(0.228)$ \\
\hline $\begin{array}{l}\text { Interdisciplinary research } \\
\text { collaboration }\end{array}$ & $3.44(4.20)$ & $3.44(4.38)$ & $-0.197(0.844)$ \\
\hline
\end{tabular}

\subsection{Measures and variables}

In order to analyse which factors are associated with collaboration, the dependent variables are total numbers of research collaborations, numbers of disciplinary research collaborations and numbers of interdisciplinary research collaborations. We use a broad definition of research collaboration as 'working closely with others to produce new knowledge, or to develop or apply existing knowledge'. ${ }^{9}$ Interdisciplinary research collaboration is 'working closely with researchers from disciplines different from your own to produce new knowledge, or to develop or apply existing knowledge'. After reading these definitions, respondents were

\footnotetext{
${ }^{9}$ We follow Bozeman and Corley (2004, p.600) in using this quite open definition, and 'permitting the respondent to determine what is and is not collaboration' in relation to the various terms contained within this definition.
} 
asked to self-report how many research collaborations they had and, separately, how may interdisciplinary research collaborations they had. To calculate numbers of disciplinary collaborations we subtracted the number of interdisciplinary collaborations from the total number of collaborations. Most studies of collaboration use the number of research collaborators (Bozeman and Corley, 2004; Bozeman and Gaughan, 2011) as the dependent variable, although van Rijnsoever and Hessels (2011) also use research collaborations. The total number of research collaborations in which a researcher has been involved naturally grows over the course of the career. We asked about the number of collaborations in the past ten years, as it was not realistic to expect respondents with fifty year careers in social science to remember all their collaborations. This had the advantage of framing the survey around collaborations within proximate socio-political and policy contexts.

The concern of our statistical models is to estimate which factors contribute to the volume of collaboration activity. The second is to discern any difference in relevant factors, or the extent of their contribution to the models, when comparing total collaboration, disciplinary collaboration and interdisciplinary collaboration. The main factors included were related to the duration of an individual research career, and the diversity of experience contained within each career trajectory. Our models included three main independent variables designed to test the significance of these factors in relation to participation in collaborations First, in terms of career diversity we measured the number of previous jobs in total and in different types of organizations. We did not limit ourselves to numbers of previous organizations as other studies have done (van Rijnsoever and Hessels, 2011). Changes in position within an organisation may reflect transitions within the 'organisational career' process of a scientific career (Gläser and Laudel 2007 \& 2008), potentially also reflecting changes in opportunities or strategies for research collaboration. To try and ensure only significant job changes within an organisation were included by respondents we specified this in the questionnaire, using the example of promotion to a higher level position in contrast to a contract renewal in the same position as a guide.

Second, a measure of the internationalization of SS research workforce was developed as a proxy for diversity of career experience, utilizing citizenship information. Applicants were asked to nominate whether they were Australian citizens only, held multiple citizenships including Australian, or were temporary or permanent residents in Australia. In our regression analyses we test whether there are significant differences in numbers of collaborations between those who hold Australian citizenship only and the rest of the respondents. In this 
study we cannot control for normal processes of 'scientific mobility' (Mahroum, 2000) in relation to international experience and collaboration opportunities. We therefore assume the same level of scientific mobility across citizenship and residency categories in our data. Positive values in regression results are considered attributable to enlarged professional networks, linguistic and cultural connections, non-restrictive citizenship policies and migration benefits, and not to differential international mobility within science careers. Negative values could be attributed to a lack of local networks or encountering different professional norms, for example. Also in relation to international experience, as part of our first independent variable we asked respondents how many previous jobs they had held in foreign universities and we also test this factor in our model.

Third, we included a measure of an individual's overall research orientation toward discovery or application. Hagstrom (1965) argued that applied research was inherently more interdisciplinary. However, the relationship between applied research and interdisciplinary collaboration is both supported (Carayol and Thi, 2005; van Rijnsoever and Hessels, 2011) and questioned (Schummer, 2004) in the literature. The orientation of individual researchers toward knowledge creation or application will vary, and may also impact on their propensity to become involved in interdisciplinary research. Little is currently known about the orientation of social science researchers in terms of conducting basic or applied research, or about how this might intersect with interdisciplinarity (Porter et al., 2007; Porter and Rafols, 2009). However, it seems likely that the 'type of research activity' (OECD, 2002) that a social scientist is predominantly oriented toward will influence the level of their involvement in interdisciplinary collaboration. For these reasons we included this variable in our models. We measured 'research orientation' using a seven-point Likert-type scale with 'pure basic research' at one end, 'applied research' at the opposite end, and 'strategic basic research' in the middle. Other studies have used a simple dichotomy between basic and applied disciplines (van Rijnsoever and Hessels, 2011). We chose to use a continuous scale allowing respondents to self-report on their research orientation, rather than assigning a value on the basis of their discipline. This reflects the diversity of types of research activity within disciplines (Becher and Trowler, 2001).

A number of control variables were included in our models. Gender was included as some studies have found men have more research collaborators than women (Bozeman and Corley, 2004; Lee and Bozeman, 2005), although more recently Bozeman and Gaughan (2011) found no difference in the number of collaborators by gender. There is also some evidence that 
women tend to collaborate more with other women in universities (Boardman and Corley, 2008) and professional networks (Ibarra, 2003). Rhoton and Firman (2007) found that women are more attracted to interdisciplinary collaboration. Likewise, van Rijnsoever and Hessels (2011) found that while there is no difference between men and women in total numbers of collaborations, women have more interdisciplinary collaborations than men. As a control for career duration, we included years of experience ${ }^{10}$. In addition, Van Rijnsoever and Hessels (2011) found a positive relationship between dynamics of the scientific field and disciplinary collaboration. They defined this as 'the extent to which an individual researcher experiences their own scientific field to change’ (van Rijnsoever and Hessels, 2011, p.465). We measured this by asking respondents to what extent they agreed with the statement 'the research field in which I work is highly dynamic', using a five-point Likert-type scale ranging from strongly disagree to strongly agree. We converted the results into a dichotomous variable in our model.

The questionnaire also asked about public support measures, in this case sources of research funds. Participants were asked to nominate their main funding source for their research collaborations, from a comprehensive list of public and private sources. These results were categorized into a dichotomous variable comparing the major source of national competitive research grants among social scientists, the Australian Research Council (ARC), to all other sources of funding. As the ARC encourages interdisciplinary research applications within the national competitive grants program it administers, this variable was included in our model to control for differential access to support from the ARC for interdisciplinary research. As we have respondents from different organization types, we included a dummy variable to distinguish between employment in higher education and other sectors.

Finally, some transformations in the selected variables are needed. Our models include continuous variables that are asymmetric due to the existence of a higher number of low values, which can skew the outputs of the analysis. For 'number of previous jobs' (Australian universities, foreign universities, firms, government departments and other relevant institutions) and 'years of experience' we used Kolmogorov-Smirnov test to determine whether their distributions match a normal distribution. To solve the absence of normality found, we applied a logarithmic transformation ${ }^{11}$ to these variables. To facilitate the interpretation of the results in the bivariate analysis, the variables associated with 'number of

\footnotetext{
${ }^{10}$ Although the measurement of academic rank is a traditional proxy of career duration, we included years of experience because our study includes a significant group of respondents (15\%) that are currently employed outside universities.

${ }^{11}$ Taking into account that the variables can be 0 , we used the logarithmic transformation: $\log (\mathrm{x}+1)$
} 
previous jobs' and 'years of experience' and have been recoded into two categories, using the median of each variable as cut-off (because none follows a normal distribution).

\section{Analysis and results}

Descriptive statistics for the variables are shown in Table 2. A small majority (53\%) were male. A total of $61.1 \%$ of the respondents held Australian citizenship only, whilst $26.7 \%$ held dual or multiple citizenships including Australia. The remaining 12.3\% were foreign citizens temporarily or permanently resident in Australia. The mean number of previous jobs held was at least one for the majority of the organization types. The vast majority of the respondents are working in the higher education sector.

Prior to our regression analysis we checked if there were differences in total numbers of research collaborations and/or numbers of interdisciplinary collaborations according to respondents' personal and research career characteristics (Table 3). Due to the absence of normality in these variables we used a non-parametric test, specifically U-Mann Whitney. The numbers of previous university jobs, both in Australia and abroad, are indicators of increased collaboration and interdisciplinary collaboration. Having held a previous government research job was an indicator of higher numbers of interdisciplinary collaborations. Researchers with international citizenships have more collaborations than those with Australian citizenship only, although this difference is reduced for interdisciplinary collaboration. The more applied the research the higher the number of both total collaborations and interdisciplinary collaborations. Researchers who perceive they work in a dynamic field also have more collaborations. 
Table 2. Descriptive statistics

\begin{tabular}{|c|c|c|c|c|}
\hline & Mean & S.D. & Median & $\mathrm{n}$ \\
\hline \multicolumn{5}{|l|}{ Continuous variables } \\
\hline Total research collaborations & 5.3 & 5.7 & 4 & 645 \\
\hline Interdisciplinary research collaborations & 3.1 & 4.3 & 2 & 645 \\
\hline Previous Australian university jobs & 2.6 & 2.5 & 2 & 620 \\
\hline Previous foreign university jobs & 0.7 & 1.2 & 0 & 620 \\
\hline Previous jobs in firms & 1.1 & 2.0 & 0 & 620 \\
\hline Previous government organization jobs & 1.2 & 2.2 & 0 & 620 \\
\hline Previous jobs in other relevant institutes & 0.5 & 1.4 & 0 & 620 \\
\hline Research orientation & 4.82 & 1.7 & 5 & 574 \\
\hline Years of work experience & 13.2 & 11.5 & 11 & 637 \\
\hline Dynamics of the scientific field & 4.1 & 0.8 & 4 & 584 \\
\hline \multicolumn{5}{|l|}{ Categorical variables } \\
\hline Citizenship & \multicolumn{3}{|c|}{ International-->38.9\% } & 643 \\
\hline Gender & \multicolumn{3}{|c|}{ Male --> 52.7\% } & 641 \\
\hline Employment & \multicolumn{3}{|c|}{ Higher education --> 81.6\% } & 618 \\
\hline Research funds & \multicolumn{3}{|c|}{ Australian Research Council --> 44\% } & 518 \\
\hline
\end{tabular}


Table 3. Numbers of research collaborations

\begin{tabular}{|c|c|c|}
\hline & $\begin{array}{c}\text { Total } \\
\text { collaboration } \\
\end{array}$ & $\begin{array}{c}\text { Interdisciplinary } \\
\text { collaborations }\end{array}$ \\
\hline \multicolumn{3}{|l|}{ Previous Australian university jobs } \\
\hline$<=2$ & 5.10 & 2.98 \\
\hline$>2$ & 6.21 & 3.60 \\
\hline P-value & $\mathrm{p}<0.01$ & $\mathrm{p}<0.01$ \\
\hline \multicolumn{3}{|l|}{ Previous foreign university jobs } \\
\hline 0 & 4.75 & 2.75 \\
\hline$>0$ & 7.00 & 4.11 \\
\hline P-value & $\mathrm{p}<0.01$ & $\mathrm{p}<0.01$ \\
\hline \multicolumn{3}{|l|}{ Previous jobs in firms } \\
\hline 0 & 5.51 & 3.26 \\
\hline$>0$ & 5.65 & 3.20 \\
\hline$P$-value & n.s. & n.s. \\
\hline \multicolumn{3}{|c|}{ Previous government department or research organization jobs } \\
\hline 0 & 5.55 & 3.11 \\
\hline$>0$ & 5.57 & 3.39 \\
\hline P-value & n.s. & $\mathrm{p}<0.01$ \\
\hline \multicolumn{3}{|l|}{ Previous other relevant institution jobs } \\
\hline 0 & 5.66 & 3.18 \\
\hline$>0$ & 5.26 & 3.40 \\
\hline$P$-value & n.s. & n.s. \\
\hline \multicolumn{3}{|l|}{ Citizenship } \\
\hline Australian only & 4.72 & 2.66 \\
\hline International & 6.35 & 3.83 \\
\hline P-value & $\mathrm{p}<0.01$ & $\mathrm{p}=0.04$ \\
\hline \multicolumn{3}{|l|}{ Research orientation $^{\mathrm{a}}$} \\
\hline Pure basic research & 4.73 & 2.43 \\
\hline Strategic basic research & 5.73 & 3.34 \\
\hline Applied research & 6.50 & 3.85 \\
\hline P-value & $\mathrm{p}=0.01$ & $\mathrm{p}=0.02$ \\
\hline \multicolumn{3}{|l|}{ Gender } \\
\hline Male & 5.86 & 3.26 \\
\hline Female & 4.76 & 2.94 \\
\hline P-value & n.s. & n.s. \\
\hline \multicolumn{3}{|l|}{ Employment } \\
\hline Other & 4.87 & 2.92 \\
\hline Higher education & 5.70 & 3.30 \\
\hline P-value & n.s. & n.s. \\
\hline \multicolumn{3}{|l|}{ Years of work experience } \\
\hline$<=11$ & 3.90 & 2.28 \\
\hline$>11$ & 6.93 & 4.03 \\
\hline$P$-value & $\mathrm{p}<0.01$ & $\mathrm{p}<0.01$ \\
\hline \multicolumn{3}{|l|}{ Dynamics of the scientific field } \\
\hline No & 4.65 & 2.33 \\
\hline Yes & 6.13 & 3.64 \\
\hline P-value & $\mathrm{p}<0.01$ & $\mathrm{p}<0.01$ \\
\hline \multicolumn{3}{|l|}{ Research funds } \\
\hline Australian Research Council & 6.42 & 3.54 \\
\hline Other & 5.98 & 3.82 \\
\hline P-value & n.s. & n.s. \\
\hline
\end{tabular}

Note: n.s. $=$ no significant. ${ }^{a}$ Variable converted into a variable with three categories for better interpretation of the differences. 


\subsection{Findings for statistical tests of hypotheses}

Table 4 shows results for a negative binomial regression. As mentioned above, the dependent variables in this case are count variables. Attention has been drawn to risks associated with traditional statistical methods, such as linear regression, analysis of variance or correlations, to analyze such variables (McCullagh, 1980). The reference model for count data is the Poisson regression, nevertheless, the equidispersion assumption is rarely met ${ }^{12}$. We used the variation coefficient to measure the assumption of equidispersion (Lindsey, 1995). Both the number of research collaborations and interdisciplinary research collaborations coefficients are more than 1 indicating the existence of overdispersion. As others have done (Bozeman and Gaughan, 2011), we estimated the econometric specifications outlined using a negative binomial model, which better captures the nature of the dependent variables analyzed (Cameron and Trivedi, 1998).

The table shows six regressions, columns (1) and (2) for total research collaboration, columns (3) and (4) for disciplinary research collaboration and columns (5) and (6) for interdisciplinary research collaboration. The odd-numbered columns include as independent variable the total number of previous jobs, and the even-numbered columns divide these jobs by type of employer organization (university, firm, government or other institutes).

\footnotetext{
${ }^{12}$ It has been argued that even in the simplest settings large overdispersion leads to grossly deflated standard errors and grossly inflated t-statistics in the usual maximum likelihood output, and hence it is important to use Poisson regressions given robust variance estimator (Cameron and Trivedi, 2005, p. 670). We replicate our results with this methodology and we obtain more or less the same results as those reported in Table 4. The biggest differences are the absence of signification in the variable "dynamic of the scientific field" in all regressions and the sign of employment change from negative to positive, which means the importance of higher educations in the collaborations.
} 
Table 4. Negative binomial models for numbers of collaborations

\begin{tabular}{|c|c|c|c|c|c|c|}
\hline & \multicolumn{2}{|c|}{ Total Research collaboration } & \multicolumn{2}{|c|}{ Disciplinary collaboration } & \multicolumn{2}{|c|}{ Interdisciplinary collaboration } \\
\hline & (1) & (2) & (3) & (4) & (5) & (6) \\
\hline \multicolumn{7}{|l|}{ Independent variables } \\
\hline Previous jobs (ln) & $0.256 * * *(0.061)$ & & $0.196 \dagger(0.112)$ & & $0.289 * * *(0.082)$ & \\
\hline Previous Australian university jobs (ln) & & $0.211 * * *(0.056)$ & & $0.244 * *(0.103)$ & & $0.176^{* *}(0.077)$ \\
\hline Previous foreign university jobs (ln) & & $0.295^{* * *}(0.070)$ & & $\begin{array}{c}0.332 * * * \\
(0.129)\end{array}$ & & $0.263 * * *(0.095)$ \\
\hline Previous jobs in firms (ln) & & $0.028(0.050)$ & & $0.030(0.092)$ & & $0.016(0.068)$ \\
\hline $\begin{array}{l}\text { Previous government department or } \\
\text { research organization jobs (ln) }\end{array}$ & & $0.036(0.053)$ & & $-0.067(0.099)$ & & $0.132 \dagger(0.072)$ \\
\hline Previous other institution jobs (ln) & & $-0.026(0.073)$ & & $-0.124(0.136)$ & & $0.034(0.098)$ \\
\hline Citizenship [International] & $0.242 * * *(0.068)$ & $0.118(0.077)$ & $0.142(0.126)$ & $-0.008(0.142)$ & $0.323 * * *(0.092)$ & $0.228 * *(0.104)$ \\
\hline Research orientation & $0.064 * * *(0.021)$ & $0.078 * * *(0.021)$ & $0.047(0.038)$ & $0.066 \dagger(0.038)$ & $0.074 * * *(0.028)$ & $0.082 * * *(0.028)$ \\
\hline \multicolumn{7}{|l|}{ Control variables } \\
\hline Gender [Female] & $-0.140 * *(0.069)$ & $-0.145^{* *}(0.071)$ & $-0.279 * *(0.126)$ & $-0.282 * *(0.129)$ & $-0.038(0.093)$ & $-0.037(0.096)$ \\
\hline Employment [Higher education] & $-0.178(0.129)$ & $-0.169(0.129)$ & $-0.040(0.237)$ & $0.008(0.237)$ & $-0.273(0.174)$ & $-0.246(0.175)$ \\
\hline Years $(\ln )$ & $0.151^{* * *}(0.041)$ & $0.107 * *(0.042)$ & $0.082(0.074)$ & $0.014(0.077)$ & $0.188 * * *(0.055)$ & $0.161 * * *(0.058)$ \\
\hline Dynamics of the scientific field & $0.206^{* *}(0.095)$ & $0.213^{* *}(0.094)$ & $0.080(0.170)$ & $0.103(0.169)$ & $0.311^{* *}(0.130)$ & $0.311^{* *}(0.130)$ \\
\hline Research funds [ARC] & $0.008(0.070)$ & $-0.003(0.070)$ & $-0.241 \dagger(0.129)$ & $-0.222 \dagger(0.128)$ & $0.189 * *(0.095)$ & $0.175 \dagger(0.095)$ \\
\hline Intercept & $0.317(0.213)$ & $0.606 * * *(0.202)$ & $0.116(0.385)$ & $0.311(0.365)$ & $-0.695(0.290)$ & $-0.414(0.276)$ \\
\hline Number of observations & 563 & 563 & 563 & 563 & 563 & 563 \\
\hline Chi-squared & $73.038 * * *$ & $86.90 * * *$ & $19.376^{* *}$ & $30.12 * * *$ & $61.78 * * *$ & $74.974 * * *$ \\
\hline Thetha & $2.256(0.184)$ & $2.334(0.193)$ & $0.599(0.053)$ & $0.620(0.055)$ & $1.229(0.108)$ & $1.241(0.110)$ \\
\hline Pseudo $\mathrm{R}^{2}$ & 0.57 & 0.58 & 0.31 & 0.32 & 0.45 & 0.45 \\
\hline
\end{tabular}


To capture the goodness of fit of the model, we calculate the value of the chi-square tests that are always significant, suggesting that the models fit the data. The theta parameter shown is the dispersion parameter and appears to be acceptably low. ${ }^{13}$ In addition, the values of Rsquared move between $31 \%$ and 58\%. The low correlations among independent variables are a symptom of the absence of multi co-linearity problems (see Appendix A for correlation matrix).

Table 4 presents the results for the proposed regressions. In general terms, number of previous jobs is an important factor influencing all types of collaborations. However, looking at specific types of employer organizations, the number of previous jobs in both Australian and foreign universities have a positive and significant relationship with total collaborations and both disciplinary and interdisciplinary collaborations. No significant relationships were found for other organization types. Hypothesis 1 can therefore be considered as largely supported.

Although international citizenship appears to be an important determinant of collaboration, the distinction between disciplinary and interdisciplinary collaboration show that it is a particularly important variable for the latter. Hypothesis 2 is thus partly supported. An orientation toward applied research is positively and significantly related to the number of interdisciplinary collaboration. Hypothesis 3 is therefore supported. As in the previous case, an applied research orientation is also positively and significantly related to total numbers of research collaboration.

The sign of the coefficient for the gender control is negative in all three models, although it is not significant for interdisciplinary collaborations. This means that women have significantly less collaborations in the total and disciplinary collaboration models. In line with the results of van Rijnsoever and Hessels (2011), a positive and significant relationship exists between perceiving your research field to be dynamic and both total and interdisciplinary collaboration. Of the other control variables, a positive and significant relationship exists between the length of the career and both total collaboration and numbers of interdisciplinary collaborations.

\footnotetext{
${ }^{13}$ Note that R parameterizes this differently from SAS, Stata, and SPSS. The R parameter (theta) is equal to the inverse of the dispersion parameter (alpha) estimated in these other software packages.
} 


\section{Discussion of results}

The importance of prior experience in expanding collaboration in social science is clear in our results. The number of previous jobs is a strong predictor of higher numbers of collaborations. Interestingly, this seems to be more important for boosting interdisciplinarity than for disciplinary collaboration. In terms of the diversity of previous jobs, universities are the organization type linked to increased collaboration. The international dimension is also important, with foreign university jobs also associated with increased collaboration. The only other organization type that appears to have any importance at all in our models is government jobs and this only in the case of increased interdisciplinary collaboration. Diversity of employment experience relation to the type of employing organisation is thus apparently of limited importance in boosting collaboration. Rather it seems that diversifying experience within the university academic career path, via international university employment, is what contributes to greater collaboration.

The clear link between accumulated university career experience and research collaboration activity was expected. An enlarged pool of potential collaborators and opportunities for collaboration are presented by organisation changes. The same applies to the international dimension of university employment. Normally university job changes are associated with progress in organisational careers toward higher level positions. Access to higher academic ranks are associated with stable access to resources and hence the security to try new research directions that may not succeed (Gläser and Laudel, 2007 \& 2008). This too can open the way for new collaborations to occur, particularly if stability enables a researcher to take more risks - such as expanding their cognitive interests via interdisciplinarity.

The importance of international experience for expanding collaboration is reinforced by the results for international citizenship. As a proxy for cultural affiliations and expanded social capital networks, international citizenship can be seen to benefit collaboration activity. However, in this case the boost is to interdisciplinary collaboration activity and not to disciplinary collaboration. It is interesting to speculate on possible explanations for links between personal connections and/or cultural embeddedness abroad and heightened involvement in interdisciplinary collaboration. One contributing explanation may be that being motivated to address local/regional research challenges in countries outside Australia contributes to an increased involvement in problem-solving activities that require an interdisciplinary knowledge and skill base. 
Overall, our findings regarding internationalisation of the social science workforce in Australia are quite pronounced. The results suggest, first, that broad-based population policies such as dual citizenship may have a beneficial effect on the extent of research collaboration and interdisciplinarity. As others have suggested, it is probably time to think more clearly about migration and global mobility from knowledge capital (Williams, 2007) and innovation systems (Hart, 2006) perspectives. In terms of knowledge capital, it is in the nature of the social sciences themselves to be enriched by socio-economic and cultural expertise and connections. Opening up the social, cultural and geographic spaces of social science research can be in this sense understood as a favouring the emergence of new patterns of collaborative relationships.

Second, specific measures that encourage extended stays by visiting researchers, such as transparent bureaucratic processes, relatively open labour market access and provision of health care (including for immediate family members), are also likely to be playing a role. Not all population policies need to focus on permanent settlement (Khoo 2014), as a degree of ‘stepping stone’ mobility is inevitable in highly skilled careers. From an innovation systems perspective, the harmonisation of transversal social policy settings - such as those guaranteeing access to social services and those promoting researcher mobility - can help to prevent barriers to the movement of knowledge and skills across disciplinary and geographic frontiers. Our results suggest Australia is already benefiting significantly from incoming social science researchers; current general population policies may be on the right track. To further develop understanding of these issues, international cooperative and comparative studies of the way disciplinary and interdisciplinary collaborations are forged across national and innovations systems frontiers, including the role played by highly skilled migrants, may well develop policy relevant knowledge in the future.

There is also an association between whether a researcher is oriented toward applied research and their participation in interdisciplinary collaborations. The literature reviewed suggested that a nexus between applied research and interdisciplinary collaboration may exist due to the focus on problem-solving that requires diverse knowledge and skill bases. The limited evidence for this nexus comes largely from research on STEM fields. Our results suggest a similar nexus may be found in the social sciences. Alliances between medical and public health professionals are one such nexus that historically links STEM and SS fields (Rosenfeld 1992). Further research is required to substantiate whether this apparent association between an applied research orientation and interdisciplinary collaborations is, first, built around 
problem-solving areas and, second, linked to social and economic development and emergent societal challenges. Another question of interest is whether such an apparent association contributes to the bridging of divides between STEM and SS fields, or whether interdisciplinarity is largely between SS disciplines or with the related humanities field.

Among our control variables, it is interesting that while women have less disciplinary collaborations than men, there is no apparent gender difference regarding interdisciplinary collaboration. This result might be explained by well-established factors leading to gender imbalance within traditional academic careers (Ackers, 2004; Fox, 2010; Fox et al., 2011; Shauman and Noonan, 2007). Perhaps interdisciplinary collaborations allow women researchers to break free of traditional disciplinary disadvantages to some extent. Other studies have even found that women are more inclined toward interdisciplinary collaboration (Rhoton and Pfirman, 2007; van Rijnsoever and Hessels, 2011), however our results do not support this finding for the SS. From a policy point of view the association of our control for dynamics of the scientific field with higher numbers of research collaborations is also interesting. If researcher's sense of changing field conditions is linked more to interdisciplinary collaborations than more traditional disciplinary collaborations, then perhaps policies encouraging the mobilization of diverse types of knowledge around societal challenges are bearing fruit. On this point is it also noticeable that there is no association between project funding from the Australian Research Council and the level of collaboration activity, except in relation to interdisciplinary collaborations.

A comparison between our models for disciplinary and interdisciplinary collaboration is instructive. Increased disciplinary collaboration appears to not be driven by any factors outside the number of previous university jobs. A traditional cognitive and peer community career path (Gläser and Laudel, 2007 \& 2008) leads to increased collaboration as social capital networks expand (Bozeman et al. 2001) and access to institutional power grows (Bourdieu 1975). In contrast, interdisciplinary collaboration is driven by additional factors including holding an international citizenship and an orientation toward applied research. Interdisciplinary collaboration is also associated with longer careers and perceptions of working in a dynamic field of science. These results point toward a finding that interdisciplinary collaboration, the application of knowledge and emerging research challenges are somewhat linked together in the SS. This result is particularly interesting in the context of recent research that suggests that SS research may be differently useful to society, when compared with STEM research, and that SS researchers feel as much demand for their 
work from direct users as do STEM researchers (Olmos-Peñuela et al. 2013b). Our findings would suggest that SS researchers use interdisciplinary collaborations as one pathway to meeting this demand from societal end-users.

\section{Conclusions}

This paper has investigated the research collaborations of social scientists. Using data from a survey of authors of SS journal articles working in Australia we investigated three main issues. First, we revealed the extent to which social scientists are involved in interdisciplinary collaboration as part of their overall portfolio of research collaborations. Second, we investigated researchers' professional and personal characteristics that are correlated with participation in research collaborations. Finally, we analysed which of these factors are linked to participation in disciplinary and/or interdisciplinary research collaborations.

Our results suggest the following findings. First, social scientists' self-reporting of total numbers of collaborations and numbers of interdisciplinary collaboration suggest that interdisciplinary collaborations constitute a very considerable part of overall collaborative activity. Second, SS collaboration is positively influenced by the number of prior Australian and foreign university jobs, the holding of an international citizenship and a personal orientation toward applied research. The results also show that social scientists who are oriented toward applied research have both the highest numbers of collaborations overall and the highest numbers of interdisciplinary collaborations. In terms of our theoretical assumptions about research careers, these factors can be interpreted as enhancing the diversity of career experience and enlarging the professional and personal networks through which collaborators can be found. Augmenting S\&T human capital (Bozeman et al. 2001), through job changes and international experience and/or connections has benefits for participation in research collaborations and, particularly, for participation in interdisciplinary collaborations.

From the perspective of policy-makers, there does appear to be an existing nexus between collaboration, applied research and interdisciplinarity in SS. However, precise definitions of existing patterns of interdisciplinary and applied research collaborations involving SS researchers are lacking. Clearly, more extensive research on SS collaborations and their links to societal benefits are required to bolster this conclusion. However, our results suggest that reductions in investment in SS research may have negative consequences for existing collaborative relationships that have precisely the characteristics of interdisciplinarity and applied orientation that are valorised as being associated with societal benefits in policy 
circles. It also appears that specific support measures that encourage diversity of experience in SS careers will produce benefits in terms of expanding the level of SS collaboration. Further, it seems that measures directed toward applied research challenges are more likely to produce benefits in term of interdisciplinary collaboration. Strategies aiming to expand these activities may need to differentiate between: 1) incentives for new collaborations; 2) measures supporting established applied research collaborations, with possible incentives to enhance interdisciplinary participation; and 3) supporting the transition of established interdisciplinary collaborators to new or high priority topics. The significance of experience in our results suggests support measures should be available across the length of research careers, with type 1) measures, above, more targeted at researchers in the early stages of an established independent research trajectory, and type 3) measures more targeted at senior or even elite level researchers. Policy settings that support international participation in the SS labour force and which facilitate mobility abroad, including extended stays, also may be important for enhancing collaboration. This appears to be particularly so in the case of interdisciplinary collaboration, although a fuller explanation for this apparent connection needs to be explored.

The results presented in this paper are subject to limitations that should also be addressed by future research. First, the sampling procedure could not expect to capture a representative sample of professional social scientists as the frame was limited to publishing social scientists as a sample of active researchers - and then to those publishing in journals indexed in the SSCI. Second, the survey response rate was quite low, although it was comparable to other recent studies of collaboration (van Rijnsoever and Hessels, 2011). Third, the Australian context has its own specificities, so care must be taken in generalizing from the results. Finally, the major limitation of our methodological approach is that the substantive characteristics of interdisciplinary interactions remain masked. The extent to which interdisciplinary collaborations involving social scientists bring together complementary skills to undertake discrete modular tasks or to forge hybrid cognitive approaches, for example, remains an important topic for future research. 


\section{References}

Ackers, H.L., 2004. Managing Work and Family Life in Peripatetic Careers: The Experiences of Mobile Women Scientists in the European Union. Women's Studies International Forum 27(3), 189-201.

Ackers, H.L., 2009. Moving People and Knowledge: Scientific Mobility in an Enlarging European Union. Edward Elgar, Cheltenham UK.

Barry, A., Born, G., Weszkalnys, G., 2008. Logics of interdisciplinarity. Economy and Society 37, 1, 20-49.

Beaver, D., 2001. Reflections on scientific collaboration (and its study): past, present and future. Scientometrics 52, 365-377.

Beaver, D., Rosen, R., 1978. Studies in scientific collaboration Part I. Scientometrics 1, 6584.

Becher, T., Trowler, P.R., 2001. Academic Tribes and Territories, second edition. SRHE and Open University Press, Maidenhead, Berkshire.

Blau, P.J., 1994. The Organization of Academic Work. Transaction, New Brunswick, NJ.

Boardman, P.C., Corley, E.A., 2008. University research centers and the composition of research collaborations. Research Policy 37, 900-913.

Bornmann, L. 2013. What is societal impact of research and how can it be assessed? A literature review. Journal of the American Society for Information Science and Technology 64(2): 217-233.

Bourdieu, P., 1975. The specificity of the scientific field and the social conditions of the progress of reason. Social Science Information, December 14, 19-47.

Bozeman, B., Corley, E., 2004. Scientists' collaboration strategies: implications for scientific and technical human capital. Research Policy 33, 599-616.

Bozeman, B., Dietz, J., Gaughan, M., 2001. Scientific and technical human capital: an alternative model for research evaluation. International Journal of Technology Management 22 (7/8), 716-740.

Bozeman, B., Fay, D. and Slade, C. 2013. Research collaboration in universities and academic entrepreneurship: the state-of-the-art. Journal of Technology Transfer 38: 1-67.

Bozeman, B. Gaughan, M., 2007. Impact of grants and contracts on university academics interactions with industry. Research Policy 36: 694-707.

Bozeman, B. Gaughan, M., 2011. How do men and women differ in research collaborations? An analysis of the collaborative motives and strategies of academic researchers. Research Policy 40, 1393-1402.

Bruce, A., Lyall, C., Tait, J., Williams, R., 2004. Interdisciplinary integration in Europe: the case of the Fifth Framework Program. Futures 36, 457-470.

Butler, L., 2003. Explaining Australia's increase share of ISI publications - the effects of a funding formula based on publication counts. Research Policy 32, 143-155.

Cameron, A., Trivedi, P. 1998. Regression analysis of count data. Cambridge University Press, Cambridge.

Cameron, A. Trivedi, P. 2005. Microeconometrics: methods and applications, Cambridge University Press, Cambridge.

Carayol, N., Thi, T.U.N., 2005. Why do academic scientists engage in interdisciplinary research? Research Evaluation 14 (April (1)), 70-79.

CEC, 2005. Commission Staff Working Document. Implementation Report 2004 on "A mobility strategy for the European Research Area" and "Researchers in the ERA: one profession, multiple careers”. Brussels, 6.4.2004 SEC(2005)474.

Chompalov, I., Genuth, J., Schrum, W., 2001. The organization of scientific collaborations. Research Policy 31, 749-767.

Clark, B. 2011. Influences and conflicts of federal policies in academic-industrial scientific collaboration. Journal of Technology Transfer 36(5), 514-545.

Crane, D., 1972. The Invisible College. University of Chicago Press, Chicago. 
Cronin, B., Overfelt, K., 1994. Citation-based auditing of academic performance. Journal of the American Society for Information Science 45(2), 61-72.

Cruz-Castro, L., Sanz-Menéndez, L., 2010. Mobility versus job stability: Assessing tenure and productivity outcomes. Research Policy 39, 27-38.

Delamont, S., Atkinson, P., Parry, O., 2000. The doctoral experience: success and failure in graduate school. Routledge, London.

D’Este, P., Fontana, R., 2007. What drives the emergence of entrepreneurial academics? A study on collaborative research partnerships in the UK. Research Evaluation, 16(4), 257270.

D’Este, P., Perkmann, M . 2011. Why do academics engage with industry? The entrepreneurial university and individual motivations. The Journal of Technology Transfer 36(3): 316-339.

DIAC (Department of Immigration and Citizenship), 2011. Population Flows. Commonwealth of Australia, Canberra.

Díaz de Rada, V., 2005. The Effect of Follow-up Mailings on The Response Rate and Response Quality in Mail Surveys. Quality \& Quantity 39, 1-18

Dietz, J., Bozeman, B., 2005. Academic careers, patents, and productivity: industry experience as scientific and technical human capital. Research Policy 34, 349-367.

DIISR (Department of Industry, Innovation, Science and Research), 2011. Evaluation of the International Science Linkages Program. Commonwealth of Australia, Canberra.

Edwards, D., Radloff, A., Coates, H., 2009. Supply, Demand and Characteristics of the HDR Population in Australia. Australian Centre for Education Research, Melbourne, downloaded from http://research.acer.edu.au/higher_education/10

Endersby, J.W., 1996. Collaborative Research in the Social Science: Multiple Authorship and Publication Credit. Social Science Quarterly 77 (2), 375-392.

Ensign, P.C. (2009) Knowledge Sharing Among Scientists. Palgrave MacMillan, New York.

Etzkowitz, H., Webster, A., Gebhardt, C., Terra, B.R.C., 2000. The future of the university and the university of the future: evolution of ivory tower to entrepreneurial paradigm. Research Policy 29 (2), 313-330.

European Commission Research Directorate-General, 2007. The Seventh Framework Programme (FP7): Taking European Research to the Forefront. Brussels, European Communities Publications Office.

Fernández-Zubieta, A., 2009. Recognition and weak ties: is there a positive effect of postdoctoral position on academic performance and career development? Research Evaluation 18(2): 105-115.

Flaherty, L. M., Pearce, K. J., Rubin, R. B., 1998. Internet and face-to-face communication: Not functional alternatives. Communication Quarterly 46(3), 250-268.

Foray, D., Gibbons, M., 1996. Discovery in the context of application. Technological Forecasting and Social Change 53: 263-277.

Fox, M.F.,2010. Women and men faculty in academic science and engineering: social organizational indicators and implications. American Behavioral Scientist 53, 997-1012.

Fox, M.F., Fonseca, C., Bao, J., 2011. Work and family conflict in academic science: Patterns and predictors among women and men in research universities. Social Studies of Science, 41(October), 715-535.

Fricker, S., Galesic, M., Tourangeau, R., Yan, T., 2005. An experimental comparison of web and telephone surveys. Public Opinion Quarterly 69(3), 370-392.

Gaughan, M., Corley, E., 2010. Science faculty at US research universities: the impacts of university research center affiliation and gender on industrial activities. Technovation 30, 215-222.

Gibbons, M., Limoges, C., Nowotny, H., Schawartzman, S., Scott, P., Trow, M., 1994. The New Production of Knowledge: The Dynamics of Science and Research in Contemporary Societies. Sage, London. 
Gläser, J., 2012. How does Governance change research content? On the possibility of a sociological middle-range theory linking science policy studies to the sociology of scientific knowledge. Technical University Berlin, Technology Studies Working Papers, TUTS-WP-1-2012, (downloaded on 1 April 2012 from: http://www.ts.tu-berlin.de/vmenue/publikationen/tuts-working_papers/)

Gläser, J., Laudel, G., 2007. Evaluation without Evaluators: The impact of funding formula on Australian University Research. In R. Whitley and J. Gläser (Eds.), The Changing Governance of the Sciences: The Advent of Research Evaluation Systems. Springer, Dordrecht, 127-151.

Gläser, J., Laudel, G., 2008. From apprentice to colleague: the metamorphosis of early career researchers. Higher Education 55(3), 387-406.

Hagstrom, W., 1965. The Scientific Community. Basic Books, New York.

Hart, D., 2006. Understanding Immigration in a National Systems of Innovation Framework. Science and Public Policy 34(1), 45-53

Ibarra, H., 2003. Homophily and Differential Returns: Sex Differences in Network Structure and Access in an Advertising Firm. Administrative Science Quartely 37(3), 422-447.

Jonkers, K., 2010. Mobility, Migration and the Chinese Scientific Research System. Routledge, London.

Katz, J.S., Martin, B.R., 1997. What is research collaboration? Research Policy 26 (March (1)), 1-18.

Khoo, S.-E., 2014. Attracting and Retraining Globally Mobile Skilled Migrants: Policy Challenges based on Australian Research. International Migration 52(2): 20-30.

Klein, J.T., 1990. Interdisciplinarity: History, Theory, Practice. Wayne State University Press, Detroit.

Klein, J.T., 2000. A Conceptual Vocabulary of Interdisciplinary Science. Ch. 1 in P. Weingart and N. Stehr (Eds.), Practising Interdisciplinarity. University of Toronto Press, Toronto, 3-24.

Krishna, V.V., Khadria, B., 1997. Phasing Scientific Migration in the Context of Brain Gain and Brain Drain in India. Science, Technology and Society 2(2), 348-385.

Lam, A. 2011. University-industry collaboration: careers and knowledge governance in hybrid organisational space. International Journal of Strategic Business Alliances, 2(1), 135-145.

Latour, B., Woolgar, S. 1986. Laboratory Life: The Construction of Scientific Facts, $2^{\text {nd }}$ Edition. Princeton University Press, Princeton.

Laudel, G., 2002. What do we measure by co-authorships? Research Evaluation 11 (April (1)), 3-15.

Laudel, G., Origgi, G., 2006. Introduction to a special issue on the assessment of interdisciplinary research, Research Evaluation 15(1), 2-4.

Leahey, E., Reikowsky, R.C., 2008. Research specialization and collaboration patterns in sociology. Social Studies of Science 38, 425-440.

Lee, S., Bozeman, B., 2005. The impact of research collaboration on scientific productivity. Social Studies of Science 35 (October (5)), 673-702.

Lee, Y.S. 1996. 'Technology transfer' and the research university: a search for the boundaries of university-industry collaboration. Research Policy 25, 843-863.

Levin, S.G., Stephan, P.E., 1991. Research Productivity Over the Life Cycle: Evidence for Academic Scientists. The American Economic Review Vol. 81, No. 1, 114-132

Lin, M., Bozeman, B., 2006. Researchers' industry experience and productivity in universityindustry research centers: a scientific and technical human capital explanation. Journal of Technology Transfer 31, 269-290.

Lindsey, J.K., 1995. Modelling frecuency and count data. Oxford University Press, Oxford.

Liu, Y., Rafols, I., Rousseau, R., 2012. A framework for knowledge integration and diffusion. Journal of Documentation, Vol. 68 No.1, 31-44. 
McCullagh, P., 1980. Regression Models for Ordinal Data. Journal of the Royal Statistical Society. Series B (Methodological) 42(2), 109-142.

Maasen, S. 2000. Inducing Interdisciplinarity: Irresistible Infliction?. In P. Weingart and N. Stehr (Eds.), Practising Interdisciplinarity. University of Toronto Press, Toronto, 194-214.

Mahroum, S. 2000. Scientific Mobility: an agent of scientific expansion and institutional empowerment. Science Communication 21(4), 367-378.

Martin, B. R., Irvine, J., 1983. Assessing basic research: Some partial indicators of scientific progress in radio astronomy, Research Policy 12, 61-90.

Matthews, M., Biglia, B., Henadeera, K., Desvignes-Hicks, J.-F., Faletic, R., Wenholz, O., 2009. A Bibliometric Analysis of Australia’s International Research Collaboration in Science and Technology: Analytical Methods and Initial Findings. FEAST Discussion Paper 1/09, Australian National University, Canberra.

Mauss, M. (1950) [1990], The Gift: The Form and Reason for Exchange in Archaic Societies (Foreword by Mary Douglas) trans. W. D. Halls. W.W. Norton \& Company, New York.

Melin, G., 2000. Pragmatism and self-organization - research collaboration on the individual level. Research Policy 29, 31-40.

Merton, R.K., 1973. The Sociology of Science: Theoretical and Emprical Investigations. University of Chicago Press, Chicago.

OECD, 2002. Fascati Manual. OECD, Paris.

O’Kane, M., 2008. Collaborating to a purpose: Review of the Cooperative Research Centres Program. Commonwealth of Australia, Canberra.

Olmos-Peñuela, J., Castro Martínez, E., D'Este, P. 2014a. Knowledge transfer activities in social sciences and humanities: Explaining the interactions of research groups with nonacademic agents. Research Policy 43: 696-706.

Olmos-Peñuela, J., Benneworth, P.,Castro Martínez, E. 2014b. Are STEM from Mars and SSH from Venus?: Challenging disciplinary stereotypes of research's social value. Science and Public Policy 41(3): 384-400.

Perkmann, M., Tartari, V., McKelvey, M., Autio, E., Broström, A., D’Este, P., Fini, R., Geuna, A., Grimaldi, R., Hughes, A., Krabel, S., Kitson, M., Llerena, P., Lissoni, F., Salter, A., Sobrero M. (2013) Acadmic engagement and commercialisation: A review of the literature on university-industry relations. Research Policy 42: 423-442.

Porac, J., Wade, J., Fischer, H., Brown, J., Kanfer, A., Bowker, G., 2004. Human capital heterogeneity, collaborative relationships, and publication patterns in a multidisciplinary scientific alliance: a comparative case study of two scientific teams. Research Policy 33, 661-678.

Porter, A. L., Cohen, A. S., Roessner, J. D., Perreault, M., 2007. Measuring researcher interdisciplinarity. Scientometrics 72(1), 117-47.

Porter, A.L., Rafols, I., 2009. Is science becoming more interdisciplinary? Measuring and mapping six research fields over time. Scientometrics 81 (3), 719-745.

Price, D. de Solla, 1963. Little Science, Big Science...And Beyond. Columbia University Press, New York.

Productivity Commission, 2007. Public Support for Science and Innovation. Commonwealth of Australia, Canberra.

Rafols, I., Meyer, M., 2010. Diversity and network coherence as indicators of interdisciplinarity: case studies in bionanoscience, Scientometrics, 82(2), 263-87.

Rhoton, D., Pfirman, S., 2007. Women in interdisciplinary science: exploring preferences and consequences. Research Policy 36 (February (1)), 56-75.

Rosenfeld, P.L., 1992. The Potential of Transdisciplinary Resarch for Sustaining and Extending Linkages between the Health and Social Sciences. Soc. Sci. Med. 35(11), 1343-1357. 
Roztocki, N., 2001. Using internet-based surveys for academic research: Opportunities and problems. Proceedings of the 2001 American Society for Engineering Management (ASEM) National Conference, 290-295.

Sánchez Fernández, J., Muñoz Leiva, F., Montoro Ríos, F. J., 2009. ¿Cómo mejorar la tasa de respuesta en encuestas on line? Revista de Estudios Empresariales. Segunda época 1, 4562.

Saxenian, A., 2006. The New Argonauts: Regional Advantage in a Global Economy, Harvard University Press, Cambridge, Mass.

Schummer, J., 2004. Multidisciplinarity, interdisciplinarity, and patterns of research collaboration in nanoscience and nanotechnology. Scientometrics 59, 425-465.

Shapin, S. 1994. A Social History of Truth. Chicago University Press, Chicago.

Shauman, K.A., Noonan, M.C., 2007. Family migration and labor force outcomes: sex differences in occupational context. Social Forces 85, 1735-1764.

Sheehan, K.B., 2001. E-mail survey response rates: A review. Journal of Computer-Mediated Communication 6(2), 0. DOI: 10.1111/j.1083-6101.2001.tb00117.x

Shrum, W., Chompalov, I. and Genuth, J. 2001. Trust, Conflict and Performance in Scientific Collaborations. Social Studies of Science 31(5): 681-730.

Song, H., 1997. From Brain Drain to Reverse Brain Drain: Three Decades of Korean Experience. Science, Technology and Society 2(2), 317-345.

Tappeiner, G., Tappeiner, U., Walde, J., 2007. Integrating disciplinary research into an interdisciplinary framework: A case study in sustainability research. Environmental Model Assessment 12, 253-256.

Tartari, V., Breschi, S. 2012. Set them free: scientists' evaluations of the benefits and costs of university-industry research collaboration. Industrial and Corporate Change, 21(5): 11171147.

Tartari, V., Salter, A., D’Este, P. 2012. Crossing the Rubicon: exploring the factors that shape academics' perceptions of the barriers to working with industry. Cambridge Journal of Economics 36(3): 655-677.

Turpin, T., Garrett-Jones, S., 2000. Mapping the New Cultures and Organization of Research in Australia. Ch. 5 in Peter Weingart and Nico Stehr (eds.) Practicising Interdisciplinarity. University of Toronto Press, Toronto, 79-109.

Turpin, T., Garrett-Jones, S., Woolley, R. 2011. Cross-sector collaboration in Australia: The Cooperative Research Centres Program at the Crossroads. Science and Public Policy, 38(2), 87-98.

Turpin, T., Woolley, R., Marceau, J., 2010. Scientists across the boundaries: national and global dimensions of science and technology human capital and policy implications for Australia. Asia and Pacific Journal of Migration 19(1), 65-86.

Ubfal, D., Maffioli, A. 2011. The impact of funding on research collaboration: Evidence from a developing country. Research Policy 40: 1269-1279.

van Rijnsoever, F.J., Hessels, L.K., 2011. Factors Associated with disciplinary and interdisciplinary research collaboration. Research Policy 40, 463-472.

Vinck, D. 2010. The Sociology of Scientific Work. Edward Elgar, UK.

Wagner, C.S, 2005. Six case studies of international collaboration in science. Scientometrics 62, 3-26.

Whitley, R., 2000. The Intellectual and Social Organization of the Sciences, second edition. Oxford University Press, Oxford.

Whitley, R., Gläser, J., Engwall, L., 2010. Reconfiguring knowledge production: changing authority relationships in the sciences and their consequences for intellectual innovation. OUP, Oxford.

Wilcoxon, F., 1945. Individual Comparisons by Ranking Methods. Biometrics Bulletin 1(6), 80-83. 
Williams, A.M., 2007. International labour migration and tacit knowledge transactions: a multi-level perspective. Global Networks 7, 29-50.

Woolley, R., Turpin, T., Marceau, J., Hill, S., 2008. Mobility Matters: Research Training and Network Building in Science. Comparative Technology Transfer and Society, 6(3), 159-186.

Wray, K.B., 2005. Rethinking Scientific Specialization. Social Studies of Science 35(1), 151164.

Ziman, J., 1994. Prometheus Bound: Science in a Dynamic Steady State. Cambridge University Press Cambridge, UK.

Ziman, J., 2000. Real Science: What It Is and What It Means. Cambridge University Press, Cambridge UK. 
Appendix A

Correlation matrix

\begin{tabular}{|c|c|c|c|c|c|c|c|c|c|c|c|}
\hline & 1. & 2. & 3. & 4. & 5. & 6. & 7. & 8. & 9. & 10. & 11. \\
\hline 1. Previous Australian University (ln) & 1 & & & & & & & & & & \\
\hline 2. Previous foreign universities (ln) & 0.057 & 1 & & & & & & & & & \\
\hline 3. Previous firms (ln) & $0.142 * * *$ & $0.224 * * *$ & 1 & & & & & & & & \\
\hline $\begin{array}{l}\text { 4. Previous government departments or } \\
\text { research organizations (ln) }\end{array}$ & 0.037 & $0.106 * * *$ & $0.231 * * *$ & 1 & & & & & & & \\
\hline 5. Previous other relevant institutions (ln) & $0.097^{* * *}$ & $0.111 * * *$ & $0.260 * * *$ & $0.371 * * *$ & 1 & & & & & & \\
\hline 6. Citizenship & $-0.100 * * *$ & $0.365 * * *$ & 0.003 & $-0.100 * * *$ & -0.006 & 1 & & & & & \\
\hline 7. Research orientation & -0.053 & -0.064 & 0.007 & $0.172 * * *$ & $0.091 * *$ & -0.041 & 1 & & & & \\
\hline 8. Gender & $0.124 * * *$ & $-0.209 * * *$ & $-0.099 * * *$ & -0.032 & 0.016 & $-0.126 * * *$ & $0.105^{* * *}$ & & L & & \\
\hline 9. Employment & $0.181 * * *$ & 0.058 & $-0.089 * *$ & $-0.225 * * *$ & $-0.147 * * *$ & 0.061 & $-0.119 * * *$ & 0.06 & 1 & & \\
\hline 10. Years (ln) & $0.377^{* * *}$ & $0.210 * * *$ & 0.008 & $-0.097 * *$ & -0.021 & $0.101 * * *$ & $-0.102 * *$ & -0.044 & $0.625 * * *$ & 1 & \\
\hline 11. Dynamics of the scientific field & -0.04 & 0.048 & -0.019 & 0.018 & 0.001 & 0.047 & $0.138 * * *$ & 0.078 & 0.06 & 0.058 & \\
\hline 12. Research funds & $-0.101 * *$ & -0.017 & 0.07 & $0.093 * *$ & $0.104 * *$ & -0.055 & $0.212 * * *$ & 0.037 & $-0.272 * * *$ & $-0.275 * * *$ & -0.028 \\
\hline
\end{tabular}

